\title{
O SILÊNCIO NÃO É A MELHOR ARMA: MISOGINIA E VIOLÊNCIA CONTRA AS MULHERES NO GAME LEAGUE OF LEGENDS
}

\author{
Silence is not the weapon of choice: Misogyny and violence against women in \\ the League of Legends Game
}
El silencio no es la mejor arma: Misoginia y violencia contra las mujeres en el juego League of Legends

Andrea Meyer Landulpho Medrado Vice-Coordenadora e Professora do Programa de Pós-Graduação em Mídia e Cotidiano da Universidade Federal Fluminense andreamedrado@yahoo.com.br

Adler Ariel Moreno Mendes Mestre pelo Programa de Pós-Graduação em Mídia e Cotidiano da Universidade Federal Fluminense mendes.adler@gmail.com

\section{Resumo}

O objetivo deste artigo é dar voz a um público que vem sendo marginalizado no universo dos games: as mulheres. Analisamos de que maneiras um ambiente sexista estaria contribuindo para práticas de silenciamento na indústria dos games e principalmente no cotidiano das mulheres que jogam. Para investigar essa questão, selecionamos um jogo, o League of Legends (LoL), distribuído pela Riot Games. As perspectivas teóricas percorrem discussões sobre o papel do marketing, das representações de personagens femininas e da predominância de um "boys club", que contribuem para a exclusão das mulheres. Com base em observações participantes e em entrevistas com jogadoras, argumentamos que as empresas desenvolvedoras de games precisam exercer um papel mais incisivo no combate às práticas misóginas.

Palavras-chave: Games. League of Legends. Misoginia.

\begin{abstract}
This article aims to give a voice to women gamers as they have been systematically marginalised in this environment. We analyse the ways in which a sexist culture might contribute to silencing women who work in the industry and, particularly, women who play games in their everyday lives. To delve into these issues, we selected one game, League of Legends $(L o L)$, distributed by Riot Games. Our theoretical perspectives include discussions about the role of marketing, the representation of female characters and the predominance of a "boys clubs". All these elements contribute to the exclusion of women. Drawing from ethnographic observations and interviews with women players, we argue that the gaming companies must play a stronger role in fighting misogynous practices.
\end{abstract}

Key words: Games. League of Legends. Misogyny. 


\section{Resumen}

El propósito de este artículo es dar voz a una audiencia que ha sido marginada en el mundo de los juegos: las mujeres. Analizamos la manera como un entorno sexista podría estar contribuyendo para silenciar a las mujeres en la industria del juego y a las mujeres que juegan cotidianamente. Para investigar este problema, seleccionamos un juego, League of Legends $(L o L)$, distribuido por Riot Games. Las perspectivas teóricas se desarrollan a través de discusiones sobre el papel del marketing, las representaciones de personajes femeninos y el predominio de un "boys club", que contribuyen a la exclusión de las mujeres. Con base en observaciones etnográficas y entrevistas con jugadoras, argumentamos que los desarrolladores de juegos deben desempeñar un papel más importante en la lucha contra las prácticas misóginas.

Palabras clave: Juegos. League of Legends. Misoginia.

\section{INTRODUÇÃO}

"Vai lavar roupa", "vai lavar louça", "tinha que ser mulher pra fazer merda" são apenas algumas das agressões direcionadas às mulheres gamers em fóruns de jogos. Para lidar com um ambiente tóxico, essas mulheres têm que recorrer ao silenciamento dos chats, à alteração de seus nomes para nomes neutros ou masculinos, à busca de apoio entre grupos de mulheres nas redes sociais ou a reclamações às empresas detentoras dos jogos. Essas observações nos conduzem ao objetivo principal da pesquisa: escutar as mulheres, um público que vem sendo marginalizado no universo dos games. Nosso problema de pesquisa contempla a seguinte questão: de que formas as mulheres são empurradas para práticas de silenciamento, tanto na indústria dos games como no cotidiano das jogadoras?

Para analisar essas questões, vamos nos debruçar sobre um jogo, o League of Legends (LoL), que foi lançado em 2009 e distribuído pela Riot Games. O LoL é um jogo inserido na categoria de Multiplayer Online Battle Arena (MOBA) que faz sucesso na indústria dos games. Essa categoria consiste em inserir mais de uma pessoa, conectada via internet, fazendo-as "combater" em uma arena virtual. Em League of Legends, os jogadores são chamados de "invocadores". Em outras palavras, são aqueles que controlam um personagem. Atualmente existem 141 campeões, com habilidade específica que, junto do time, enfrentam outros "invocadores" ou jogam contra a "máquina".

Com relação à abordagem metodológica, optamos por nos inspirar na tradição etnográfica (PINK et. al, 2016) ${ }^{1}$, com observações participantes e diários produzidos pelos

\footnotetext{
${ }^{1}$ Estamos cientes dos debates que ocorrem na área com relação à melhor terminologia para nos referimos à etnografia conduzida online. Termos como etnografia virtual, netnografia e webnografia vêm sendo utilizados por diversos autores como Christine Hine, Robert Kozinets e Stephen Dann, respectivamente. Essas diferentes terminologias são abordadas com atenção em um capítulo sobre abordagens etnográficas, de Suely Fragoso,
} 
pesquisadores nos ambientes do jogo. Aqui, como afirma Mônica Machado (2017, p. 28) temos um “[...] debate da cultura digital a partir de um viés antropológico" e que se refere também à imersão característica da experiência etnográfica e ao quanto é possível incorporar interpretações e descrições densas ao processo de pesquisa. Dessa forma, o olhar antropológico, dotado de riqueza de detalhes, pode oferecer uma contribuição significativa para os estudos de games. Em seguida, conduzimos dez entrevistas em profundidade com jovens jogadoras, realizadas durante o evento Geek \& Game Rio Festival, no dia 21 de julho de 2018. Maiores detalhes sobre os procedimentos metodológicos adotados serão fornecidos na próxima seção deste artigo.

Nossas perspectivas teóricas incluem discussões com relação ao papel do marketing para fortalecer a exclusão das mulheres, representações simplistas e objetificadas das personagens femininas e o conceito de "boys club", além da incorporação do conceito de dialogismo de Bakhtin (2014) aplicado às dinâmicas excludentes do game LoL. Com base em nossa pesquisa, argumentamos que o domínio masculino nas indústrias de games, esteja ele estruturado de forma intencional ou não, tem sido utilizado para consolidar e moldar essas indústrias de formas que contribuem para excluir as mulheres e marginalizá-las como profissionais e jogadoras (sendo este último aspecto o foco principal deste artigo).

\section{A INDÚSTRIA E O MARKETING DE GAMES COMO FERRAMENTAS DE EXCLUSÃO}

Dados da empresa Newzoo, obtidos em 13 países, revelam que as mulheres correspondem a $46 \%$ do número total de gamers. No Brasil, esse número é ainda mais significativo. Segundo uma pesquisa feita pela Game Brasil 2018, realizada pelo Sioux Group, Blend New Research, ESPM e Go Gamers, as mulheres são a maioria entre os gamers, representando um total de 58,9\% ${ }^{2}$. A partir dessa constatação, surgiu nossa primeira inquietação: por que, mesmo sendo maioria nesse universo, poucas mulheres se identificam abertamente como jogadoras? Ainda no estágio exploratório da pesquisa, em agosto de 2017, tínhamos elaborado e distribuído questionários para jogadores de outro jogo não abordado neste artigo, o Counter-Strike Global Offensive (GS:GO), através da comunidade no

Raquel Recuero e Adriana Amaral (2011). No entanto, essa discussão está além do escopo da proposta deste artigo. Aqui, optamos utilizar a terminologia etnografia digital por esta referir-se a uma abordagem mais ampla, destacada dos estudos de marketing e consumo que são mais associados à etnografia. Além disso, observamos que o termo "etnografia virtual" encontra-se datado, sendo mais pertinente a um momento anterior da internet, quando havia uma distinção mais forte entre o real e o virtual.

${ }^{2}$ Disponível em: https://dialogando.com.br/somos-todos-gamers/ Acesso em: 13 de outubro de 2018 
Facebook "CS: GO - competitivo". No entanto, mesmo tendo obtido 1.278 respostas, apenas 30 mulheres haviam respondido os questionários, o que correspondia ao ínfimo número de 2,4\% dos participantes. Qual o porquê de um número tão insignificante?

Uma rápida exploração do tema já nos revela algumas injustiças históricas. Cem anos antes de o hardware ter sido construído, Ada Lovelace "já havia produzido o primeiro exemplo do que mais tarde seria chamado de programação de computador" (PLANT, 1997, p. 16). O que explicaria então o fato de mulheres como Ada Lovelace, Mary Kenneth Keller, Grace Hopper, Dana Ulery, Hedy Lamarr e Kathleen Antoneli representarem nomes dos quais poucas pessoas já ouviram falar enquanto que Steve Jobs, Bill Gates e Mark Zuckerberg tornaram-se quase sinônimos das grandes invovações tecnológicas? (BBC NEWS, 2018)33.

Uma possível explicação está associada ao forte sexismo estrutural que contribui para que um número relativamente reduzido de mulheres atue em áreas ligadas à computação e à informática. Por sua vez, a participação das mulheres na indústria de games também precisa ser ampliada. Pesquisas realizadas no Reino Unido, por exemplo, revelaram que as mulheres representavam apenas $4 \%$ da força de trabalho na indústria de games naquele país (SKILLSET, 2009, apud BOGG \& PRESCOTT, 2013). Além disso, conforme aponta a professora Andreia Malucelli, em entrevista para a BBC News (2018), "de acordo com dados recentes divulgados pelo Facebook, Google, Twitter e Apple, as mulheres são apenas 30\% dos funcionários nessas empresas". A professora ainda cita o Anita Borg Institute (ABI), cuja pesquisa mostra que o número de mulheres estudantes de todos os cursos de ciência da computação corresponde a apenas $18 \%$ nos Estados Unidos. Já no Brasil, segundo o Instituto Nacional de Estudos e Pesquisas Educacionais (INEP), as mulheres representam apenas 15\% dos matriculados em cursos de tecnologia (BBC NEWS, 2018) ${ }^{4}$.

É razoável observar que o baixo número de mulheres nas áreas da computação e do desenvolvimento de games esteja ligado às determinações culturais impostas ao gênero. Para

\footnotetext{
${ }^{3}$ Ada Lovelace desenvolveu o primeiro algoritmo da história. Mary Kenneth Keller teve papel importante na criação da linguagem de programação BASIC. Dana Ullery foi a primeira mulhere engenheira da Nasa, tendo desenvolvido algoritmos para a automatização dos sisyemas Deep Space Network, de rastreamento de tempo real da agência espacial americana. A tecnologia usada nos telefones celulares e nas redes wi-fi também foi criada por uma mulher, Hedy Lamarr.

Há também Kathleen Antonelli, que com Jean Jennings Bartik, Frances Snyder Holberton, Marlyn Wescoff Meltzer, Frances Bilas Spence e Ruth Lichterman Teitelbaum programou o ENIAC, o primeiro computador eletrônico digital de propósito geral da história (BBC, 2018).
}

\footnotetext{
${ }^{4}$ As pesquisas e a entrevista foram citadas nessa matéria da BBC News, de 13/04/2018, disponível em: https://g1.globo.com/educacao/noticia/como-as-mulheres-passaram-de-maioria-a-raridade-nos-cursos-deinformatica.ghtml Acesso em: 10 de outubro de 2018
} 
piorar ainda mais o cenário, quando conseguem entrar nesse ambiente masculino, as diferenças de tratamento são assustadoras. Recentemente, a empresa Riot Games, desenvolvedora do game League of Legends foi processada por discriminação de gênero. Um dos funcionários e um ex-funcionário afirmam que a publisher apresenta um ambiente de trabalho que coloca "os homens primeiro". Tanto que, segundo os funcionários da empresa, um supervisor se recusava a promover mulheres (GUGELMIN, 2018) . $^{5}$

Há aqui um outro aspecto que precisa ser levado em consideração: a existência da cultura nerd ou geek ${ }^{67}$. Inspirados na chamada "revanche dos nerds", que ganhou o Vale do Silício - local de importância dentro da indústria de computadores, desenvolvimento tecnológico e produção de jogos digitais - esse grupo que antes era dominado e marginalizado teria se tornado agora dominante e opressor. Adrienne Massanari sugere, por exemplo, que os nerds são avessos a algumas discussões, o que ocorre, por exemplo, quando negam as problemáticas envolvendo gênero, raça e sexualidade (2017, p. 332). Obviamente, não queremos aqui aplicar generalizações que levem ao entendimento de que todo nerd ou geek possa ser taxado de misógino ou racista. De fato, o grupo é também vítima de ataques contra sua cultura, fazendo com que seus membros sejam, muitas vezes, agredidos. No entanto, como muitos autores demonstram, a cultura nerd e geek surge muitas vezes associada ao que denominam de boys club (local reservado para homens) ou boyhood. Esse conceito é trazido por Letícia Rodrigues:

O boys club exclui jogadoras como consumidoras e determina assim quem é o "real" consumidor dos jogos produzidos. As temáticas dos jogos, formas de jogabilidade e características dos personagens são configurados para jogadores (homens) partindo-se do pressuposto que, atrelado à identidade de gênero masculina, estão atributos específicos - que em teoria poderiam somente ser desfrutados por homens bem específicos: majoritariamente caucasianos e obrigatoriamente heterossexuais (RODRIGUES, 2014, p. 40).

Os videogames seriam, dessa forma, pensados e "feitos" para determinado gênero e instituídos como sendo pertencentes ao grupo masculino. Com isso, muitas mulheres chegam a mencionar que, durante a infância, consoles eram colocados no quarto de seus irmãos, diminuindo a oportunidade destas jogarem jogos de videogame e reforçando a prática como masculina” (MARGOLIS; FISHER 2002; GRANDO; GALLINA; FORTIM, 2013, p.152).

\footnotetext{
${ }^{5}$ Disponível em: https://m.tecmundo.com.br/amp/mercado/135983-riot-games-sendo-processada-discriminacaogenero.htm Acesso em: 09 de fevereiro de 2019

${ }_{6}$ Aqui apresentamos apenas uma definição geral, sem nos aprofundar nas distinções entre os termos, que são utilizados como sinônimos, já que esse aprofundamento está além do escopo deste artigo, mais voltado à discussão das questões de gênero e ambientes tóxicos em games.
} 
Para complementar o conceito de "boys club", surge também o conceito de "boyhood", mais voltado às questões de prática interna e funcionamento desses clubes masculinos:

Boyhood pode ser teorizado como uma natureza regressiva da masculinidade capitalista e de primeiro mundo, onde pressões externas forçam o homem de volta para um tipo de infância masculina sempre acessível. Os videogames no século 21 servem como um modo de regressão, uma máquina de tecnostalgia que permite a fuga, extensão e utopia, um espaço longe do feminismo, imperativos de classe e deveres familiares, assim como responsabilidades políticas e nacionais. (BURRILL, 2008, apud BLANCO, 2017, p.2).

De forma semelhante, não se pode desprezar a possibilidade de que o marketing dos games, ao longo dos anos, tenha contribuído para reforçar essa dinâmica de exclusão dos homens não-héteros e das mulheres. Algumas autoras como Beatriz Blanco observam que "os primeiros anúncios da Atari, no final da década de 1970 e início da década de 1980, por exemplo, exibiam pessoas de todas as idades e gêneros jogando videogames, sem direcionamento específico" aos públicos feminino ou masculino (2017, p. 3), como podemos ver na figura 1.

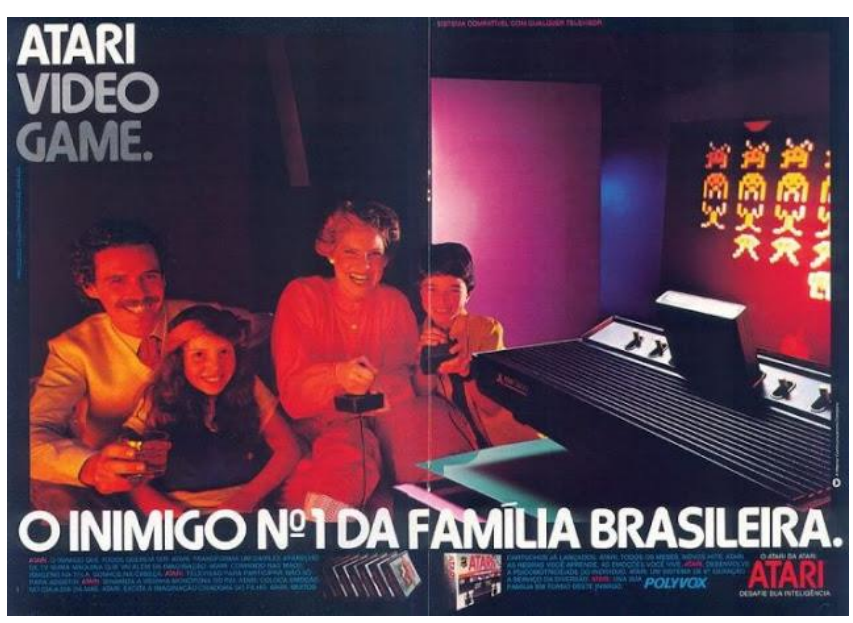

Figura 1 - Anúncio do Atari no Brasil, 1978

(Fonte: Propagandas Históricas, s.d ${ }^{8}$ )

A mudança no marketing, voltando os games para "coisa de menino" se deu em meados da década de 1980. Nesse momento, alguns autores apontam que houve uma saturação do mercado de videogames com baixa qualidade dos jogos, resultando em uma perda de confiança dos consumidores e resistência à presença de jogos muito semelhantes (LIEN, 2013). Para aquecer o mercado, a Nintendo e outras empresas começaram a fazer

8 Disponível em: https://www.propagandashistoricas.com.br/2013/02/atari-polyvox-1978.html (acesso em 04/05/2020) 
pesquisas com consumidores e observar quem jogava os games. Para facilitar esse contato, a Nintendo lançou a primeira revista especializada em jogos chamada Nintendo Power, que rapidamente se tornou a revista mais vendida para crianças. Além disso, a empresa repetiu estratégias de marketing de sucesso e desenvolveu branding através de produtos como os Cereais do Mario, as cuecas do Zelda e os notebooks Nintendo, entre outros (DONOVAN, 2010, p.171). Tudo isso facilitou traçar um perfil demográfico do consumidor, chegando à seguinte conclusão: mais garotos jogam videogames do que garotas (LIEN, 2013). Instituiu-se assim a ideia de que videogame era coisa de menino. Esse pensamento se naturalizou a tal ponto que, na década de 1990, a Nintendo lançou o GameBoy, um videogame portátil que em tradução livre seria, “jogo de garoto" (BRISTOT ET. AL., 2017, p. 863).

Além dessas questões de caráter mercadológico, ganha força uma suposta explicação biológica para justificar porque o lugar dos games estaria reservados aos homens. Ainda que não ofereçam comprovações científicas capazes de definir habilidade motoras ou intelectuais inatas atribuídas às mulheres, tais explicações biológicas passaram a ser constantemente acionadas. Como afirma Yvelise Fortim:

É apontado que as mulheres têm menos coordenação motora, acuidade visual e menos habilidades no joystick que os homens [...] Também são citadas as estratégias de gênero - os homens são mais visuais e as mulheres têm preferências por estratégias verbais e analíticas. (2008, p. 32).

Nas próximas seções deste artigo, vamos utilizar nossa pesquisa empírica para analisar questões de exclusão e até de violência contra mulheres nos ambientes gamers, tomando como base, especificamente, uma pesquisa com inspiração etnográfica do game League of Legend $(L o L)$. O estudo toma como base a pesquisa de Mestrado de Adler Mendes, um dos autores deste artigo. A coleta de dados empíricos utilizou inspiração etnográfica com a condução de observações participantes no jogo League of Legends e entrevistas em profundidade semi estruturadas com dez jogadoras durante o evento Geek \& Game Rio Festival, que ocorreu em 21 de julho de 2018. Preferimos aqui utilizar o termo "inspiração etnográfica" por este apresentar um caráter mais despretensioso já que, devido às limitações do escopo de uma pesquisa de Mestrado, só foi possível que o autor registrasse tais observações uma vez por mês, em mensários. Aqui, demonstramos consciência acerca de algumas críticas feitas por autores da área de antropologia de mídia. De fato, muitos estudos alegam ser etnográficos quando, na realidade, consistem em estudos de caráter qualitativo, 
sem a imersão no trabalho de campo necessária para que possam oferecer um conhecimento aprofundado acerca de uma cultura ou ambiente midiático (GILLESPIE, 1995).

Especificamente, essa inspiração etnográfica, que representa uma maneira mais adequada de descrever este estudo, surgiu em maio de 2017, ainda nas fases iniciais da pesquisa. No momento em que ficou decidido que o objeto de estudo seria o game League of Legends, Adler criou uma conta no mesmo e adicionou alguns amigos que começaram a ensiná-lo como jogar. O objetivo inicial era observar como se dava a relação entre os jogadores e as skins, ou itens que alteram o visual dos personagens e os efeitos de suas habilidades. Ao final de seu primeiro mês de experiência, o autor anotou todas as suas observações em um documento que denominamos de mensário. No entanto, essa fase representou uma etapa experimental. O período em que a pesquisa de campo se deu de forma sistemática ocorreu entre julho e dezembro de 2018. Ao final de cada vez, Adler escrevia suas observações em um mensário. Com isso, produziu seis mensários (Julho, Agosto, Setembro, Outubro, Novembro e Dezembro).

Vale destacar aqui que o caráter imersivo e subjetivo da pesquisa etnográfica nos permite adotar a escrita em primeira pessoa. Escrevemos, no entanto, na primeira pessoa do plural, já que este texto é fruto de um trabalho em dupla de Adler com sua orientadora de Mestrado, Andrea Medrado. Em alguns momentos nos referimos a cada um dos autores pelo nome para que possa ficar clara a participação e o papel de cada um neste artigo. Durante sua jornada de pesquisador, Adler também foi questionado pelo fato de ser homem hétero cis branco. Foi necessário realizar um processo de autorreflexão com relação ao seu lugar de fala, considerando os apontamentos de Djamila Ribeiro (2017). Aqui, vale ressaltar que, muitas vezes, esse conceito vem sendo associado à frase "fique quieto, esse não é seu lugar de fala" (RIBEIRO, 2017, p. 32), algo que seria um impeditivo ao fato de um homem, por exemplo, realizar uma pesquisa sobre misoginia em games, como é o caso neste artigo. No entanto, como esclarece Ribeiro, essa percepção não faz jus à complexidade do conceito, inspirado em discussões sobre "feminist standpoint" ou, em uma tradição literal, ponto de vista feminista. O lugar de fala implica em um reconhecimento de que "partimos de lugares diferentes, posto que experienciamos gênero de modo diferente", o que leva à "legitimação de um discurso excludente". Além disso, acrescenta Ribeiro, “quando falamos de pontos de partida, não estamos falando de experiências de indivíduos necessariamente, mas, sim, de condições sociais que permitem ou não que esses grupos acessem lugares de cidadania”. Ou seja, tratase de um debate estrutural que está mais voltado à compreensão de como o lugar social que 
certos grupos ocupam pode restringir oportunidades do que na afirmação de experiências individuais (RIBEIRO, 2017, p. 35). Dessa forma, em sua dissertação, Adler faz uma reflexão acerca de seus privilégios como jogador homem, que incluem o simples fato de, mesmo sendo um iniciante, poder jogar sem ser ofendido (MENDES, 2019).

Motivados por essas reflexões, decidimos então ouvir jogadoras mulheres de $L o L$, um dos jogos da categoria Multiplayer Online Battle Arena (MOBA) que mais faz sucesso, atualmente, na indústria dos games. Dessa forma, as observações participantes no próprio ambiente do jogo foram complementadas por dez entrevistas em profundidade semiestruturadas com jogadoras de LoL durante o evento Geek \& Game Rio Festival, no dia 21 de julho de 2018. As idades das entrevistadas variaram de 16 a 23 anos e a maioria delas era estudante no ensino médio ou curso superior (MENDES, 2019). Na próxima seção deste artigo, vamos nos debruçar acerca das perspectivas dessas jovens mulheres com relação às suas experiências cotidianas como jogadoras.

\section{SEXISMO E MISOGINIA NA INDÚSTRIA E DENTRO DOS GAMES}

É razoável assumirmos que a popularização e a acessibilidade dos games ajudaram a deflagrar comportamentos sexistas nos jogos, assim como acontece em diversos outros ambientes sociais. Com isso, demonstram características de "boys clubs" (RODRIGUES, 2014), onde jogadores se sentem, muitas vezes, à vontade para assumir atitudes que refletem uma masculinidade regressiva e tóxica (BURRILL, 2008). Como sugerimos aqui anteriormente, os personagens vistos nesses jogos são, em sua maioria, masculinos, viris, fortes, inteligentes, construídos para serem heróis e agradarem ao homem que joga.

Já a representação de personagens femininas também foi objeto de um número significativo de pesquisas no campo dos games. Algumas das categorias mais comuns de representação feminina em jogos merecem ser brevemente mencionadas aqui. Uma delas é a das personagens sedutoras, como aponta Nádia da Cruz Senna, ou aquelas que "reúnem valores definidos como puramente femininos: beleza, voluptuosidade, charme, capacidade e disposição para o amor (SENNA, 1999, p.105). Dessa forma, os ilustradores (na grande maioria das vezes homens) - inspirados por celebridades reais, como Marylin Moroe, Brigitte Bardot, Elizabeth Taylor ou Sophia Loren - pegam emprestadas características físicas, como a cintura fina, os seios e quadris fartos, a personalidades ou até roupas dessas mulheres para criarem seus traços. 
A ideia de apresentar a mulher como sedutora é estratégia recorrente dentro das produções midiáticas (seja no cinema, na televisão, na história em quadrinho ou em games). A sedução é uma das "obrigações" culturais que a mulher "precisa aprender". Logo, a sedução passa a ser uma ferramenta para a construção da mulher que é uma femme fatale (vilãs utilizam muito essa característica para conseguir fazer "maldades"); super-heroínas, que a utilizam para ganhar mais destaque entre os leitores homens; ou se manifesta na figura da mulher que vai ser resgatada nas histórias, que também usa da sedução inocente e indefesa.

No entanto, com o crescimento da presença e influência das mulheres no universo gamer, a indústria passou a ser criticada por tais representações. No entanto, mesmo com uma intensificação do debate acerca dessas questões, ainda são muitas as retaliações sofridas por mulheres da indústria que tentam questionar e romper padrões sexistas. Um dos casos mais famosos foi o chamado Gamergate. Esse evento ocorreu em 2014 quando o game Depression Quest, desenvolvido por Zoe Quinn, recebeu aprovação de toda a impressa especializada. Suspeitas do grande número de avaliações positivas começaram a surgir quando um exnamorado da desenvolvedora postou em fóruns da internet rumores acerca de uma suposta "troca sexual", de Zoe Quinn para obter uma avaliação positiva do game. Com isso, ganhou força um debate sobre a ética no jornalismo da indústria de jogos que, na verdade, representava um pretexto para manifestações violentas de misoginia e até ameaças de estupro e morte contra mulheres desenvolvedoras de games. Em quase nenhum momento a ética do jornalista ter, supostamente, se vendido foi levantada ou discutida. As críticas acabaram ficando por conta de uma mulher ter conseguido críticas positivas para o jogo desenvolvido. Para citar Renata Persicheto, em artigo elaborado para o site Tecnoblog:

\begin{abstract}
A fetichização da mulher "gamer" cai sempre que uma delas decide abrir a boca para revidar contra os incessantes assédios ou reclamar da postura dos homens que insistem em vê-las como um pedaço de carne com voz de veludo. A partir daí, o macho gamer, ao se ver tendo sua supremacia em seu ambiente natural ameaçada, passa a rechaçar a fêmea gamer e excluí-la de sua sociedade. Por quê? Porque elas são mulheres e mulheres só entram no imaginário do masculino fetichista caso respondam adequadamente às suas investidas. Caso não, Gamergates são abertos e, claro, vítimas se tornam culpadas. (PERSICHETO, 2015) 8 $\mathrm{F}^{\mathrm{i}}$
\end{abstract}

Atualmente, diversas formas de assédio continuam acontecendo dentro da indústria e se expandindo no cenário das competições de esportes eletrônicos (eSports). Outro caso marcante, que ilustra a situação enfrentada pelas mulheres jogadoras, se deu com Hanae Oseki, que já participou de diversos campeonatos de League of Legends e discutiu com um 
representante da organização New Revenge. Isso aconteceu depois que a organização se recusou a avaliar sua equipe por se tratar de um time misto (com homens e mulheres). Como aponta Ana Gabriela Coelho (2016), "segundo o representante, as equipes deveriam ser exclusivamente masculinas ou femininas, alegando a existência de 'uma lei nos esportes eletrônicos' que impedia a existência de times mistos"' . Tal justificativa, obviamente, não apresentava fundamentação legal. A situação se agravou ainda mais com novas justificativas para justificar o injustificável, como observam Daniela Cristina Menti e Denise Castilhos de Araújo:

De alguma forma, a nova justificativa conseguiu ser pior do que as primeiras. Alegando "confusão" por parte dos funcionários responsáveis pelas redes sociais, a organização explicou que, "na verdade, não são aceitos times mistos por conta das viagens para os jogos". O comunicado continua em um tom nauseante: "Se um pai de menina vê a filha viajando no meio de quatro homens, ele vai achar desagradável.” (MENTI; ARAÚJO, 2017, p.82).

Além disso, muitos xingamentos são proferidos às mulheres que tentam se aproximar desse "boys club". Quando realizamos as etapas empíricas da pesquisa, as entrevistadas sempre reclamavam de xingamentos e agressões sofridos. Pensando nisso, durante a pesquisa, colhemos capturas de tela (figura 2) encontradas em sites especializados de games, que trazem um compilado de alguns dos xingamentos mais comuns dirigidos às mulheres dentro do LoL. Após realizarmos essa coleta, categorizamos os xingamentos e ofensas. Os mais comuns foram: "Vai lavar uma louça"; "Vai lavar roupa"; "Volta para a cozinha"; "Vai pro fogão"; "Homem não perde para menina"; "Mulher só serve para sentar numa R***"; "Vou te comer"; "Malcomida"; "Mulher só serve para ser suporte"; "Vadia"; "Vagabunda"; "Tinha que ser mulher"; "Deve ser gorda"; "É por isso que estamos perdendo".

\footnotetext{
${ }^{9}$ Disponível em: https://www.redbull.com/br-pt/opiniao-o-machismo-nos-esports-nao-e-normal Acesso em: 11 de outubro de 2018
} 


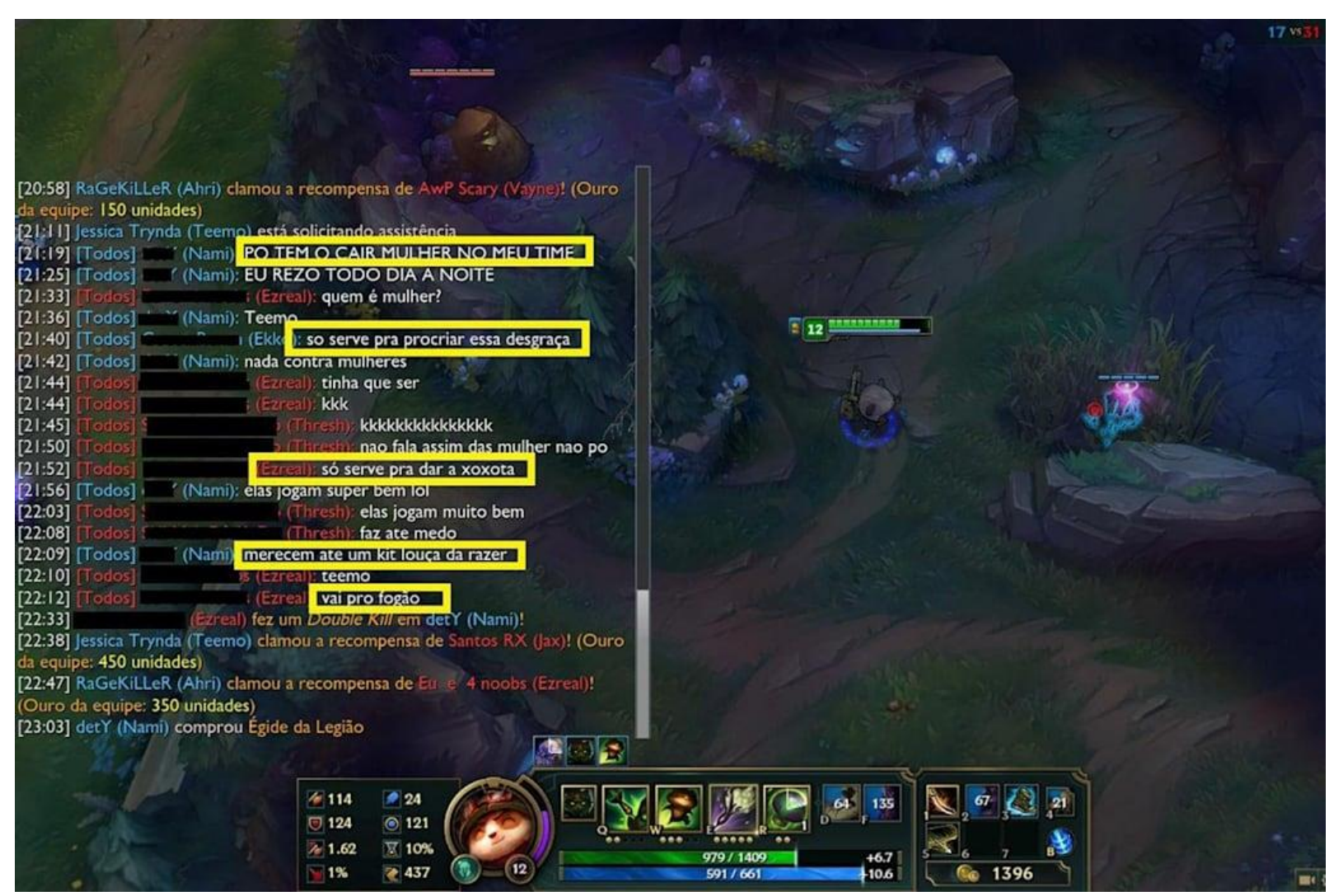

Figura 2 - Captura de tela de xingamentos contra as mulheres

Fonte: Anna Gabriela Coelho, retirado do site da Redbull (2016) ${ }^{10}$

Com base nessas capturas, categorizamos as ofensas e xingamentos misóginos como:

a) Aqueles relacionados a fazer "atividades de mulher" - Inserimos aqui os referentes aos seguintes xingamentos: "Vai lavar uma louça"; "Vai lavar roupa"; "Volta pro fogão". Classificamos essas agressões no que Bakhtin chama de dialogismo (2014, p. 43). Esse dialogismo corresponde às relações de sentido que se estabelecem entre, pelo menos, dois enunciados. Nos enunciados "estão sempre presente ecos e lembranças de outros enunciados, com que ele conta, com que ele refuta, confirma, completa, pressupõe, assim por diante" (BAKHTIN, 2014, p. 43). Assim, nessa primeira categoria as agressões são relacionadas a fazer "atividades de mulher", em contraste ao jogar videogames como "coisa de homem", como discutimos anteriormente. Dessa forma, alguns jogadores parecem se sentir pertencentes a um "grupo superior" a ponto de agredir às mulheres, relocando-as ao que acreditam ser seu verdadeiro lugar: na cozinha, fazendo as atividades domésticas, passivamente, sem questionar.

b) Falas da inferioridade da mulher em relação ao homem - Inserimos nessa categoria as

10 Disponível em: https://www.redbull.com/br-pt/opiniao-o-machismo-nos-esports-nao-e-normal (acesso em 04/05/2020)

\section{ANIMUS Revista Interamericana de Comunicação Midiática E-ISSN 2175-4977 | v.19 n.39| 2020 | www.ufsm.br/animus}


seguintes ofensas: "Homem não perde para menina" e afins. Além do dialogismo, levantado na categoria anterior, há uma marca linguística que traz um novo fator de afirmação da hierarquia e da superioridade: homem versus menina. Homem se liga ao adulto, já formado, com opinião própria, que não precisa se submeter a ninguém. Em oposição à menina (ao invés de mulher), que ainda está formação de opinião, que precisa ser educada. Ela representa assim uma criança e é consequentemente inferior. Com isso, deslegitima-se qualquer fala que a mulher, retratada como uma menina, possa ter. Em se tratando da questão do game, ainda podemos somar a isso, que o termo garota ou menina carrega, também, uma suposta falta de habilidade, já que a criança (menina ou menino) não tem, em tese, a cognição necessária para jogar bem ${ }^{11}$.

c) Falta de habilidade da mulher - representada pelas seguintes ofensas: "mulher só serve para ser suporte"12ii. Isso pode ser observado também em outros discursos, como quando alguém está fazendo algo mal feito e é repreendido com a célebre frase: "Faz como homem" ou "Joga como homem". Esse enunciado silencia a mulher como possível boa jogadora, colocando o homem como o único ser capaz de realizar tudo corretamente.

d) Xingamentos relacionados ao ato sexual - Adicionamos nessa categoria xingamentos como: "Mulher só serve para sentar numa R***"; "Vou te comer"; "malcomida"; "vadia", "vagabunda" e afins. Apresentam as agressões mais comuns e mais violentas, segundo as capturas de tela (figura 4) colhidas na internet. Além disso, esses tendem as ser os xingamentos mais denunciados pelas mulheres gamers nos fóruns do jogo e nas entrevistas que realizamos. Como apresentado no início da categorização do presente artigo, esses enunciados se relacionam com o conceito de dialogismo proposto por Bakhtin, pois os homens (subentende-se que mulheres não se tratariam assim) que escrevem ou dizem esses xingamentos estão reproduzindo uma ideia da mulher que foi construída com outros discursos ao passar do tempo. Isso também se dá em função da sexualização, desumanização e objetificação na representação da mulher nos próprios games (SENNA, 1999) e na sociedade, em geral).

\footnotetext{
${ }^{11}$ Destacamos, porém, que há casos em que chamar a mulher de menina ou chamar o homem de menino não se aplica como sendo um xingamento. De acordo com nossa experiência dentro dos games, é também comum esse tipo de tratamento principalmente dentro dos games (menina e menino; garota e garoto).

${ }^{12}$ Dentro do League of Legends existem posições que um jogador escolhe previamente antes de começar cada partida. Uma delas é a de support cuja função é defender/apoiar outra posição do game. Com isso, quem escolher jogar de support, morre diversas vezes e mata poucos adversários.
} 
Essa característica da representação feminina permite que ela esteja associada a um ato sexual que, por sua vez, foi construído ao longo do tempo como sendo de privilégio masculino. A mulher experiente na relação sexual era tradicionalmente a prostituta, com quem o homem tinha relações por prazer. Já a esposa, "a mulher de dentro de casa", foi criada para realizar atividades domésticas, servir ao homem, ser submissa. Qualquer quebra nesse código instituído era (ainda é) uma quebra à honra do pai, da família, do marido. Isso acaba sendo transmitido para um discurso masculino que chama a mulher de prostituta quando deseja puni-la ou relegá-la a um lugar de inferioridade.

Com o intuito de não serem xingadas é comum que as mulheres alterem nos jogos seus apelidos para algo neutro ou masculino. Assim, "a solução encontrada por muitas mulheres é escolher um nome em que não seja possível a identificação de seu gênero, ou mesmo o uso de um nome masculino, para que não precise passar por situações degradantes ou vexatórias.” (MENTI; ARAÚJO, 2017, p.83). Na próxima seção deste artigo, trazemos as perspectivas de mulheres jogadoras de $L o L$, que discutem suas reações, percepções e estratégias para lidar com ambientes tóxicos e misóginos nesse ambiente. Para isso, utilizamos dados de entrevistas em profundidade, que realizamos pessoalmente na feira Geek \& Game Rio Festival. Ao longo do dia 21 de julho, quando estivemos presentes no evento, conversamos com dez jogadoras de LoL. O objetivo era saber sobre o hábito de jogo delas (com quem jogavam, período do dia, tempo total semanal, etc) e como o sexismo e a misoginia afetavam esse hábito.

\section{ENTREVISTAS COM AS JOGADORAS DE LoL}

Para realizarmos a pesquisa empírica, dividimos as perguntas em três partes. Na primeira, buscamos traçar um perfil demográfico das entrevistadas tendo perguntado: idade, grau de escolaridade, profissão, tempo médio semanal gasto com o $L o L$, desde quando joga o game. Além disso, perguntamos qual personagem as entrevistadas mais gostavam. Para que pudéssemos preservar a identidade das entrevistadas, atribuímos a elas, aqui nestes artigo, os mesmos nomes de seus (suas) personagens favoritos. Por isso, também pedimos que nos oferecessem três personagens favorita(o)s a fim de evitar que duas ou mais entrevistadas recebessem a mesma denominação. $\mathrm{Na}$ segunda parte da entrevista perguntamos sobre os hábitos de jogo das entrevistadas. Já na terceira parte perguntamos sobre o ambiente sexista dentro do LoL, como a empresa detentora do jogo (Riot Games) lida com a situação e quais são as estratégias que as jogadoras utilizar para evitar ou combater os xingamentos. Na tabela 1, apresentamos informações sobre o perfil das jogadoras entrevistadas. 


\begin{tabular}{|c|c|c|c|c|c|}
\hline Apelido & Idade & Escolaridade & Profissão & $\begin{array}{c}\text { Tempo } \\
\text { semanal }\end{array}$ & $\begin{array}{l}\text { Tempo } \\
\text { jogo }\end{array}$ \\
\hline Soraka & 18 & $\begin{array}{c}\text { Médio } \\
\text { Completo }\end{array}$ & Desempregada & 24 horas & $\begin{array}{l}\text { Desde } \\
2015\end{array}$ \\
\hline Jinx & 21 & $\begin{array}{l}\text { Superior } \\
\text { Cursando }\end{array}$ & Estudante & 20 horas & $\begin{array}{c}\text { Desde } \\
2013\end{array}$ \\
\hline Sona & 16 & $\begin{array}{c}\text { Médio } \\
\text { Cursando }\end{array}$ & Estudante e Atriz & 20 horas & $\begin{array}{l}\text { Desde } \\
2013\end{array}$ \\
\hline Catlyin & 21 & $\begin{array}{l}\text { Superior } \\
\text { Cursando }\end{array}$ & Estudante & 2 horas & $\begin{array}{c}\text { Desde } \\
2013\end{array}$ \\
\hline Katarina & 23 & $\begin{array}{l}\text { Superior } \\
\text { Cursando }\end{array}$ & Estudante & 10 horas & $\begin{array}{l}\text { Desde } \\
2012\end{array}$ \\
\hline Morgana & 21 & $\begin{array}{c}\text { Médio } \\
\text { Completo }\end{array}$ & Estudante & 24 horas & $\begin{array}{c}\text { Desde } \\
2014\end{array}$ \\
\hline Lee $\operatorname{Sin}$ & 16 & $\begin{array}{c}\text { Médio } \\
\text { Cursando }\end{array}$ & Estudante e Cosplay & 21 horas & $\begin{array}{c}\text { Desde } \\
2012\end{array}$ \\
\hline Lux & 19 & $\begin{array}{l}\text { Superior } \\
\text { Cursando }\end{array}$ & Estudante & 20 horas & $\begin{array}{l}\text { Desde } \\
2012\end{array}$ \\
\hline Leona & 20 & $\begin{array}{l}\text { Superior } \\
\text { Cursando }\end{array}$ & Estudante & 20 horas & $\begin{array}{c}\text { Desde } \\
2013\end{array}$ \\
\hline Annie & 20 & $\begin{array}{l}\text { Superior } \\
\text { Cursando }\end{array}$ & $\begin{array}{c}\text { Assistente } \\
\text { Administrativa }\end{array}$ & 25 horas & $\begin{array}{c}\text { Desde } \\
2013\end{array}$ \\
\hline
\end{tabular}

Tabela 1 - Dados das entrevistadas e gasto com skins Fonte: MENDES (2019)

É interessante notar que das dez entrevistadas, seis escolheram ser reconhecidas pelos nomes de campeões que exercem, comumente, a função de suporte. Seriam elas: Soraka, Sona, Morgana, Lux, Leona e Annie. As demais - Jinx, Catlyin são atiradoras; Lee Sin é jungler e Katarina é meio. Essa posição de suporte é comumente associada ao jogador que está começando a jogar LoL e ainda não possui toda cognição necessária para desempenhar outras funções. Aqui, mesmo que algumas dessas personagens, como Morgana, Annie Lux, que jogam na posição de suporte possam exercer outras funções dentro do jogo, a maioria delas, como Thresh, Lulu, Nami, Soraka, Sona e Leona exerce a função primária de suporte. 
A motivação para jogar o game variou entre as participantes de nossa pesquisa. Algumas entrevistadas destacaram o fato da possibilidade de jogarem acompanhadas como fator mais interessante. Além disso, a rotina de jogo foi bem variada com algumas preferindo jogar com amigos e outras preferindo jogar individualmente. O horário de jogo também variou bastante entre as entrevistadas. Destacamos algumas respostas, como de Lux, que afirmou:

É um jogo viciante. Acho que assim, é um jogo que você começa e tem muita gente que joga então é muito fácil você encontrar outras pessoas que também jogam. Então, você acaba criando um vínculo de amigos maior e você se aproxima das pessoas com quem você joga. O que eu mais gosto é de jogar com meus amigos e ter esse prestígio, né?! Por isso que o $L o L$ é um jogo incomum entre muita gente. (LUX. Entrevista [21 jul. 2018]).

Direcionando-nos para o objetivo principal deste artigo, que é demonstrar o silenciamento sofrido pelas mulheres, fizemos as seguintes perguntas: Você já mudou o seu apelido ou fez alguma outra coisa no jogo para não mostrar que é mulher? Quais os motivos?, Você já sofreu algum tipo de preconceito por ser mulher dentro do jogo?, Já presenciou algum tipo de preconceito como por exemplo xingamentos contra outra mulher dentro do jogo?, Como você se defende dessas agressões?, Qual o papel da Riot Games para evitar que o preconceito contra a mulher ocorra?.

Das dez entrevistadas, três (Catlyin, Morgana e Lee Sin) afirmaram que já mudaram de apelido para um nome neutro ou masculino com o intuito de evitar comportamentos machistas. A primeira afirmou: "Já. Já tive que fazer porque teve muita gente tóxica comigo" (CATLYIN. Entrevista. [21 jul. 2018]). Morgana também seguiu essa tônica e falou: "Sim. Eu usava um nick feminino, então isso dava muito problema. Aí eu tive que mudar meu nick pra uma coisa unissex pra não ter mais esse tipo de problema” (MORGANA. Entrevista. [21 jul. 2018]).

Mesmo não tendo alterado seus nomes para fugir dos xingamentos, as demais jogadoras falaram que essa prática (de xingar alguém ao perceber que se é mulher através do nick) é algo comum. Esses movimentos de alteração de nomes nos interessam aqui não só por estarem ligados a uma luta para se apresentar como mulher no jogo e enfrentar o ambiente misógino como também pelo ato disso estar relacionado a aspectos financeiros. Para mudar de apelido no LoL é necessário o jogador ou jogadora pagar 13900 Influence Points $^{13}$ ou 1300

\footnotetext{
${ }^{13}$ Essa quantidade de IP é muito maior do que de um campeão, que custa no máximo 6300 IP.
} 
Riot Points ${ }^{14}$, fazendo a conversão para real, 1300 RPs custa R $\$ 23,50^{15}$. Ou seja, nos parece absurdo que para combater ou evitar atitudes misóginas e grotescas no jogo seja necessário que as mulheres, além de tudo, precisem pagar por isso. Também é pertubador o fato da Riot não ter apresentado uma resposta mais incisiva diante desses episódios tão comuns, como veremos mais adiante neste artigo. Percebemos então uma naturalização da dominação no ambiente do $L o L$ por uma masculinidade tóxica. As mulheres são frequentemente tratadas como incapazes e menosprezadas, sem que a Riot Games faça interferências para mudar esse cenário em que as mulheres preferem até mesmo ter que gastar dinheiro para evitar ofensas e maus tratos.

Das dez entrevistadas, todas, ou cem por cento delas, afirmaram que já passaram por situações machistas e já sofreram preconceito, ofensas ou xingamentos por serem mulheres. Destacamos a resposta de algumas entrevistadas, entre estas da jogadora Soraka:

Já! Principalmente jogando de suporte, que é onde todo mundo fala que mulher só joga de suporte. Não se dá bem em outras lanes. E foi por isso mesmo. Estava jogando de ADC e começaram a me xingar, falar um monte de coisas. Aconteceu muitas vezes comigo. (SORAKA. Entrevista. [21 jul. 2018])

Uma outra resposta que nos chamou atenção pelo alto teor misógino foi dada pela jogadora Leona, quando esta citou um exemplo que aconteceu com ela:

Quando eu tinha o nome neutro e eu falava que era garota ou percebiam que eu era garota, começavam a falar que eu era sapatão, não que fosse mentira, mas agora [quando assumiu o nome feminino] eu já fui xingada. Teve partida que eu entrei e baniram todos os campeões que eu tentava pegar e falaram que eu era vagabunda, que mulher só servia pra levar na $b^{*}$ ceta e que eu devia morrer... Isso tipo escolhendo o campeão. Ai, beleza... Falavam: 'Tinha que ser mulher pra fazer merda'. Pô, foi ótimo! Eu tenho print aqui no celular. (LEONA. Entrevista. [21 jul. 2018])

Também destacamos a resposta de Katarina, que narra xingamentos similares. A atitude para barrar o preconceito narrado pela entrevistada, também merece destaque:

Sim, vi em prints do jogo em um grupo do Facebook que eu participo em que meninos homossexuais relataram preconceito por conta do nick. Típica reprodução de machismo, dizendo que a pessoa tinha que lavar louça ou lavar roupa, que o lugar daquela pessoa não pertencia no LoL e se recusaram a continuar jogando com aquela pessoa. Quem tava nesse momento de preconceito ficou na base do jogo e se recusou a sair dali até que aquela pessoa deixasse de jogar. (KATARINA. Entrevista. [21 jul. 2018])

\footnotetext{
${ }^{14}$ Valor superior ou igual a diversas skins.

${ }^{15}$ Com esse valor é possível comprar 1380 RPs e ganhar mais alguns pontos extras. Entretanto, é o valor que mais se aproxima da mudança de nome.
} 
Com relação às formas de defesa, as mais citadas pelas jogadoras foram mutar o chat ou xingar no mesmo nível em que haviam sido xingadas. Katarina, por exemplo, falou sobre o perigo da Riot banir quem xinga de volta e, por esse motivo, foi a única que não se defendeu no mesmo momento em que foi ofendida. Como podemos ver na resposta: "Não, eu não me defendo porque o $L o L$ tem uma política contra rage e tudo mais e eu me abstenho e geralmente tiro print, muto a pessoa e no final dou ticket" (idem). Já as que mutaram o chat foram Morgana, Annie e Soraka. Destacamos a resposta da última que afirmou:

"Eu evito. Eu muto o chat. Hoje em dia tem como mutar o chat no LoL. Acho que a maioria das pessoas hoje quando começam a tomar rage, simplesmente, mutam. Até porque não tem o que ficar respondendo atos assim, entendeu?" (SORAKA. Entrevista. [21 jul. 2018])

Diante desse contexto, ficamos interessados em investigar se haveria organizações paralelas à Riot Games ou que tivessem acesso à empresa detentora do jogo que fossem capazes de levar ao conhecimento de todos essas ofensas e ataques. Por esse motivo perguntamos às jogadoras se alguém, como outros jogadores desconhecidos, amigos, ou algum grupo de mulheres, fazia algo para impedir que isso acontecesse. Das dez entrevistadas, três delas - Sona, Lee Sin e Annie - não conhecem nenhum grupo ou organização para ajudar nessa defesa. Duas entrevistadas - Jinx e Morgana - disseram que há grupos em redes sociais que ajudam essas mulheres e dão apoio, pois cada jogadora compartilha a situação de ofensa através de print screens. Enfatizamos a resposta de Morgana:

\footnotetext{
"Sim! Tem até um grupo no Facebook de meninas que jogam LoL, que vive uma motivando a outra, porque as vezes dá vontade de você desistir, né?! Por causa dessas situações, mas uma vai juntando... A gente tem um grupo, já. Jogamos juntas e é isso (MORGANA. Entrevista. [21 jul. 2018]).
}

A Riot Games também foi naturalmente citada como entidade que deveria promover a mudança desse comportamento nocivo. Soraka, por exemplo, nos lembrou que: “A Riot, às vezes, lança umas campanhas, igual aquelas LGBT, eles lançaram um tempo atrás, mas sobre a mulher, sobre coisa machista, acho que lança sim" (MORGANA. Entrevista. [21 jul. 2018]).

Ao mesmo tempo, a Riot não aparenta ter grande prestígio quando o assunto é promover uma punição efetiva para coibir esses casos. Das dez entrevistadas, apenas Soraka aparentou achar o papel da Riot minimamente suficiente. As demais entrevistadas criticaram duramente a empresa. Destacamos duas respostas. A primeira foi de Katarina ao dizer: "Não, não acho que isso é suficiente. Tem muito nick ofensivo. Já vi nick com estupro, com nazismo, já vi 
nick de... homofobia. As vezes eu acho que a Riot se omite" (KATARINA. Entrevista. [21 jul. 2018]). Ela complementa sua resposta ao narrar seus problemas com a empresa e a falta de efetividade nesses assuntos:

Olha, eu já cansei de mandar ticket pra Riot falando de algumas coisas, mas eu nunca obtenho resposta. Eles no mínimo deviam ver a partida, que eu acho que é gravada. Ver a partida e ver se realmente aconteceu, porque eles fazem, eles realmente escrevem as coisas. Então, acho que se eles dessem um pouco mais de atenção seria um pouco mais diferente. Dessem punição, banir a pessoa, entendeu? (KATARINA. Entrevista. [21 jul. 2018]).

\section{CONSIDERAÇÕES}

Com as mudanças nas estratégias de marketing de games, ocorridas no final de década de 1980 e início da década de 1990 com o intuito de aumentar as vendas, cria-se um hábito de que jogos são "coisas de menino". Isso se intensifica com algumas questões importantes que discutimos aqui anteriormente: a presença de um número relativamente pequeno de mulheres nas áreas de ciência da computação e afins, manifestações de preconceito utilizadas como mecanismos de defesa dos boys clubs (lugares reservados para os homens), e, por último, a representação sexista e objetificada das personagens femininas nos jogos. Mas quais seriam as implicações desse menor número de mulheres nessas áreas, assim também como na indústria de games, já que, como demonstramos neste artigo, há cada vez mais mulheres jogando?

Nosso estudo com inspiração etnográfica do ambiente do $L o L$ indica que participar do jogo não significa que as mulheres estejam tendo mais voz. Pelo contrário, percebemos que elas estão sendo frequentemente empurradas para práticas de silenciamento. Jogadoras mulheres são sistematicamente vistas e tratadas como menos hábeis, como pessoas que têm menos conhecimento e autoridade, quando comparadas com homens. Essa observação, com relação às jogadoras de $L o L$, não é surpreendente, se pensarmos no tratamento dispensado às mulheres da indústria de games, como nos revelou o caso ocorrido com a desenvolvedora Zoe Quinn, relatado neste artigo. Como consequência, as mulheres passam a literalmente falar menos e, quando falam, não são ouvidas.

Nossa pesquisa revelou que no $L o L$ todas essas questões se manifestaram de forma significativa. Como observamos, a comunidade do jogo revela-se, muitas vezes, tóxica e misógina. Todas as entrevistadas de nossa pesquisa declararam já terem passarado ou já terem presenciado situações de sexismo. No entanto, parecem sentir-se limitadas diante das possibilidades de combaterem esse cenário. Embora o xingar de volta, o "mutar" o chat e/ou 
recorrer a comunidades de apoio sejam todas, claro, estratégias válidas para lidar com o problema, elas não são suficientes para combatê-lo.

Assim, fica evidente que, por mais que essas dinâmicas de gênero sejam rechaçadas, elas acabam por suprimir a voz feminina, mesmo quando isso ocorre de forma involuntária. Em nosso estudo, observamos que as normas culturais e mensagens de gênero, como a problemática representação de personagens femininos, por exemplo, contribuem para moldar as regras de engajamento de uma forma desvantajosa para as jogadoras. Consequentemente, como revelam nossas entrevistas, na cultura gamer vamos percebendo um processo de socialização que não valoriza e, muitas vezes, sequer incorpora as experiências e perspectivas femininas.

Para concluir, sugerimos que, ao mesmo tempo que as práticas misóginas entre os jogadores de $L o L$ representam uma perturbadora realidade, as empresas detentoras e desenvolvedoras de games, como é o caso da Riot Games, também vêm assumindo uma postura tímida para combatê-las. Para agravar esse quadro, além da omissão com as jogadoras, denúncias sobre a enraizada cultura sexista da empresa ganharam destaque recentemente. Um exemplo disso foi a publicação, em julho de 2018, de uma matéria no site e blog especializado Kotaku, contendo denúncias anônimas de mais de 28 pessoas que já trabalharam ou trabalham na empresa (D’ANASTASIO, 2018). Diante da repercussão negativa, pouco mais de um mês após a divulgação da matéria, a Riot publicou uma resposta oficial em seu site, intitulada "Nossos Primeiros Passos Adiante" (Our First Steps Forward). Nele, a empresa oferece uma autocrítica:

Nas últimas três semanas, nos concentramos em escutar e aprender. Como empresa, estamos acostumados a resolver problemas o mais rápido possível, mas esse problema não será resolvido da noite para o dia. Precisaremos promover essa mudança em nosso DNA cultural, sem deixar espaço para sexismo ou misoginia. Inclusão, diversidade, respeito e igualdade são todos valores não negociáveis. Aos nossos funcionários, prestadores de serviços, ex funcionários e ex prestadores de serviços, pedimos desculpas. (RIOT GAMES, 2018 - nossa tradução $\left.{ }^{16}\right)$.

Embora apresente tom bem intencionado, a resposta da empresa é reveladora. Afinal, foram necessárias muitas vozes para que fossem tomados apenas "os primeiros passos". O fato de estarem sendo empurradas para o silêncio contribui para a omissão, a misoginia e a masculinidade tóxica, romantizando-as como um mal normal e comum, como se, mais do que

${ }^{16}$ Para ler a resposta completa da Riot Games, o link se encontra em nossa lista de referências. 
algo esperado, o desconforto das mulheres e o menosprezo a elas fosse simplesmente parte do jogo. E com esse jogo, a luta por uma sociedade mais justa só tem a perder.

\section{REFERÊNCIAS}

BAKHTIN, Mikhail. Marxismo e Filosofia da Linguagem. São Paulo: Hucitec, 2014.

BBC News. Como as Mulheres Passaram de Maioria a Raridade nos Cursos de Informática. 13 de abril de 2018. Disponível em: https://g1.globo.com/educacao/noticia/como-as-mulheres-passaramde-maioria-a-raridade-nos-cursos-de-informatica.ghtml (acesso em 10 de outubro de 2018).

BLANCO, Beatriz. Games para mulheres: do Girls Game Movement ao Pós Gamergate. Trabalho apresentado no GP Games do $\mathbf{4 0}^{\circ}$ Congresso Brasileiro de Ciências da Comunicação, Universidade Positivo, Curitiba, 4 a 9 de setembro de 2017. Disponível em:

http://portalintercom.org.br/anais/nacional2017/resumos/R12-0280-1.pdf. Acesso em: 06 de maio de 2020.

BOGG, Jan; PRESCOTT, Julie. The Gendered Identity of Women in the Games Industry. Eludamos Journal for Computer Game Culture, v.7, n.1, p. 55-67, 2013.

BRISTOT, Paula Casagrande; POZZEBON, Eliane; FRIGO, Luciana Bolan. A Representatividade das Mulheres nos Games. Trabalhado apresentado no XVI SBGames, PUC Paraná, Curitiba, 2 a 4 de novembro de 2017. Disponível em:

https://www.sbgames.org/sbgames2017/papers/CulturaFull/175394.pdf. Acesso em: 06 de maio de 2020.

BURRIL, Derek. Die Tryin': Videogames, Masculinity, Culture. New York: Peter Lang Publishing, 2008.

COELHO, Ana Gabriela. Discriminação com Jogadoras Mostra o Machismo Sistemático no Cenário Competitivo de eSports. Redbull, 27 de maio de 2016. Disponível em: https://www.redbull.com/brpt/opiniao-o-machismo-nos-esports-nao-e-normal. Acesso em: 11 de outubro de 2018.

D’ANASTASIO, Cecília. Inside the Culture of Sexism at Rio Games. Kotaku, 08 jul. 2018.

Disponível em: https://kotaku.com/inside-the-culture-of-sexism-at-riot-games-1828165483. Acesso em: 28 de abril de 2020.

DONOVAN, Tristan. Replay: The History of Video Games. London: Yellow Ant, 2010 (Edição Kindle).

FORTIM, Ivelise. Mulheres e Games: Uma Revisão do Tema. Trabalho apresentado no XVII SBGames, PUC Minas Gerais, Belo Horizonte, 10 a 12 de novembro de 2008. Disponível em: http://www.sbgames.org/papers/sbgames08/gameandculture/full/gc5 08.pdf. Acesso em: 06 de maio de 2020.

GILLESPIE, Marie. Television, Ethnicity and Cultural Change. London: Routledge, 1995.

GRANDO, Carolina M.; GALLINA, Luiz Melo; FORTIM, Ivelise. No Clube do Bolinha: Sentimentos e Percepções a Respeito da Presença Feminina nos Games. Trabalho apresentado no XII SBGames, Universidade Presbiteriana Mackenzie, São Paulo, 16 a 18 de outubro de 2013. Disponível em: http://www.sbgames.org/sbgames2013/proceedings/cultura/Culture- 
20_full.pdf. Acesso em: 06 de maio de 2020.

GUGELMIN, Felipe. Riot Games Está Sendo Processada por Discriminação de Gênero. Tecmundo, 07 nov. 2018. Disponível em:

https://m.tecmundo.com.br/amp/mercado/135983-riot-games-sendo-processada-discriminacaogenero.htm. Acesso em 09 de fevereiro de 2019.

LIEN, Tracey. No Girls Allowed: Unraveling the Story Behind the Stereotype of Videogames Being for Boys. Polygon features, 02 Dez. 2013. Disponível em:

https://www.polygon.com/features/2013/12/2/5143856/no-girls-allowed. Acesso em: $10 \mathrm{de}$ outubro de 2018.

MACHADO, Mônica. Antropologia Digital e Experiências Virtuais do Museu de Favela. Curitiba: Appris Editora, 2017.

MARGOLIS, Jane; FISHER, Allan. Unlocking the Clubhouse: Women in Computing. Cambridge, MA: MIT Press, 2002.

MASSANARI, Adrienne. \#Gamergate and the Fappening: How Reddit's Algorithm, Governance, and Culture Support Toxic Technocultures. New Media \& Society, v. 19, n. 3, p. 329-346, 2017.

MENDES, Adler. Mais que um Jogo: Consumo de Skins por Mulheres no Game League of Legends, 2019, 214f. Dissertação de Mestrado apresentada ao Programa de Pós-Graduação em Mídia e Cotidiano da Universidade Federal Fluminense, Niterói, Brasil, 2019.

MENTI, Daniela Cristina; ARAÚJO, Denise Castilhos de. Violência de Gênero Contra Mulheres no Cenário dos eSports. Conexão - Comunicação e Cultura, UCS, Caxias do Sul v. 16, n. 31, p. 73-88, 2017.

PINK, Sarah; HORST, Heather; POSTILL, John; HJORTH, Larissa; LEWIS, Tania; TACCHI, Jo. Digital Ethnography: Principles and Practice. Los Angeles, London, New Delhi, Singapore, Washington DC: Sage, 2016.

PERSICHETO, Renata. O Que é GamerGate e Porque Você se Importaria Com Ele. Disponível em: https://tecnoblog.net/174053/o-que-e-gamergate-estudio-pax-east/. Acesso em: 10 de setembro de 2018.

PLANT, Sadie. Mulher Digital: O Feminino e as Novas Tecnologias. Rio de Janeiro: Record, 1997.

RIBEIRO, Djamila. O que é: lugar de fala? Belo Horizonte, MG: Letramento, 2017.

RIOT GAMES. Our First Steps Forward. Riot Games Website, 28 ago. 2018. Disponível em: https://www.riotgames.com/en/who-we-are/our-first-steps-forward. Acesso em 28 de abril de 2020.

RODRIGUES, Letícia. Um Estudo em Representações Gráficas nos Jogos Eletrônicos na Perspectiva das Relações de Gênero: Os Tipos de Feminilidade em League of Legends. 2014. 171f. Trabalho de conclusão de curso - Universidade Tecnológica Federal Do Paraná, Curitiba, 2014.

SENNA, Nádia da Cruz. Deusas de Papel: A Trajetória Feminina na HQ do Ocidente. 1999. 328f. Dissertação de Mestrado - Universidade Estadual de Campinas, Campinas, 1999. 
Professora e Vice-coordenadora do Programa de Pós-Graduação em Mídia e Cotidiano e Professora do Departamento de Comunicação Social da Universidade Federal Fluminense. Doutora em Estudos de Mídia pela University of Westminster. Realizou pesquisas de pós-doutorado pela Royal Holloway University of London. Co-investigadora da rede E-Voices Redressing Marginality, com financiamento da Arts and Humanities Research Council do Reino Unido. Integrante do Grupo de Pesquisas Emerge.

Adler Mendes

Mestre pelo Programa de Pós-Graduação em Mídia e Cotidiano da Universidade Federal Fluminense (2019). Bacharel em Comunicação Social - Publicidade e Propaganda - pela Universidade Federal Fluminense (2015). Possui experiência nas áreas de cultura digital, games, direção de arte, design

gráfico e artes.

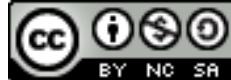

Esta obra está licenciada com uma Licença

Creative Commons Atribuição-NãoComercial-CompartilhaIgual 4.0 Internacional 